\title{
Flight Control Laws for NASA's Hyper-X Research Vehicle*
}

\author{
J. Davidson, F. Lallman, J.D. McMinn, J. Martin \\ NASA Langley Research Center, Hampton, VA \\ J. Pahle, M. Stephenson \\ NASA Dryden Flight Research Center, Edwards, CA \\ J. Selmon, Boeing, Long Beach, CA and \\ D. Bose, Analytical Methods and Associates, Austin, TX
}

\begin{abstract}
Summary
The goal of the Hyper-X program is to demonstrate and validate technology for design and performance predictions of hypersonic aircraft with an airframe-integrated supersonic-combustion ramjet propulsion system. Accomplishing this goal requires flight demonstration of a hydrogen-fueled scramjet powered hypersonic aircraft. A key enabling technology for this flight demonstration is flight controls. Closed-loop flight control is required to enable a successful stage separation, to achieve and maintain the design condition during the engine test, and to provide a controlled descent. Before the contract award, NASA developed preliminary flight control laws for the Hyper-X to evaluate the feasibility of the proposed scramjet test sequence and descent trajectory. After the contract award, a Boeing/NASA partnership worked to develop the current control laws. This paper presents a description of the Hyper-X Research Vehicle control law architectures with performance and robustness analyses. Assessments of simulated flight trajectories and stability margin analyses demonstrate that these control laws meet the flight test requirements.
\end{abstract}

\section{Introduction}

Hypersonic airbreathing propulsion is a key technology for sustained hypersonic cruise and improving the performance of space launch vehicles. Airbreathing supersonic-combustion ramjet (scramjet) engines could improve mission effectiveness by reducing on board propellant load in favor of payload or increasing operational flexibility. To mature this technology for application in the longer term, NASA has initiated the Hyper-X program (McClinton et. al 1997). The goal of the Hyper-X program is to demonstrate and validate technology for design and performance predictions of hypersonic aircraft with an airframe-integrated scramjet propulsion system. Accomplishing this goal requires flight demonstration of a hydrogen-fueled scramjet powered hypersonic aircraft. A key enabling technology for this flight demonstration is flight controls. Closed-loop flight control is required to enable a successful booster separation, to achieve and maintain the design condition during the engine test, and to provide a controlled descent. This paper presents a description of design challenges from a flight controls perspective and a description of the control law architectures with performance and robustness analyses.

\section{Hyper-X Program Overview}

The Hyper-X program is an integrated government-industry effort to demonstrate and validate the technology, the experimental techniques, and design methods for hypersonic aircraft with an airframe-integrated scramjet propulsion system. Accomplishing this goal requires flight demonstration of a hydrogen-fueled scramjet powered hypersonic aircraft. The primary objective of the flight tests is to provide data required to advance key hypersonic technology readiness levels from the laboratory to the flight environment level (McClinton et. al 1997). Three autonomous, expendable test vehicles will fly at Mach 7, 7, and 10. These vehicles, referred to as Hyper-X Research Vehicles (HXRV), are 12 feet long, five feet wide, and weight approximately $3000 \mathrm{lbs}$. (Figure 1). Each HXRV will have a single airframe-integrated scramjet, optimized for its specific test flight condition. The flights will be conducted in the Western Test Range off the California coast.

The nominal fight sequence for the Mach 7 flight is illustrated in Figure 2. Following drop from the NASA Dryden B-52 aircraft, the HXRV will be boosted to a predetermined stage separation point using a modified Orbital

\footnotetext{
* Approved for public release 6/8/99 by Hyper-X Program Office, NASA Langley Research Center, Hampton, VA 23681-0001.
} 
Pegasus booster. The HXRV will then separate from the booster and start a controlled, pre-programmed engine flight test sequence. The engine test sequence consists of a 5 second tare with power-off, the engine power-on test lasting 5-14 seconds, a 5 second power-off post-test tare, and a 15 second parameter identification maneuver (Morelli 1997). The desired test condition for the first flight is Mach 7, a dynamic pressure of $1000 \mathrm{psf}, 0$ degrees sideslip, and 2 degrees angle of attack. After the test sequence, the vehicle will fly a controlled unpowered descent trajectory. During the descent, short-duration pre-programmed test inputs, including steps and frequency sweeps, will be super-imposed on the control surface commands to aid in the estimation of aerodynamic and flight control parameters. Figure 3 shows artist conceptions of four phases of the Hyper-X flight sequence - captive carry on the NASA B-52, boost to engine test condition, separation from the booster, and engine test.

An industry team, consisting of MicroCraft, GASL, and Boeing, won the contract to develop the research vehicle, the research vehicle-to-booster adapter, and the stage separation mechanism. MicroCraft will build the vehicles and provide overall program management. GASL, Inc. is the scramjet and fuel system detail designer and builder. Boeing North American is providing guidance and control system software, and simulations; aero/thermal/structural design and analysis; and thermal protection system design and fabrication. Orbital Sciences Corp. will build the Hyper-X Launch Vehicle (HXLV), that will boost the Hyper-X Research Vehicles to the engine test conditions. In addition, Orbital has responsibility for booster control laws, integration with the HXRV, and launch test support.

\section{Flight Control Laws}

A key enabling technology for this flight test is flight controls. Closed-loop flight control is required to stabilize the HXRV and achieve the engine test condition after separation from the HXLV, then to maintain this condition during the engine test sequence. The control laws are required to maintain the desired angle of attack and sideslip to within \pm 0.5 degrees during the entire engine test sequence. After the engine test sequence, the control laws follow steering commands from the guidance system to maintain a desired descent trajectory. Before contract award, NASA developed preliminary flight control laws for the Hyper-X Research Vehicle to evaluate the feasibility of the proposed scramjet test sequence and descent trajectory (Lallman et al. 1997). After contract award, a Boeing/NASA partnership worked to develop and refine the current control laws.

The flight control function is accomplished by processing guidance commands and sensor feedbacks to produce aerodynamic surface commands. The aerodynamic control surfaces available on the HXRV are: symmetric and differential deflection of the all-moving wings (AMW), and twin rudders. Longitudinal and lateral-directional control laws were developed for angle of attack ( $\mathrm{AOA}$ ) and bank angle control, respectively (See Figure 4). The control laws were designed in the continuous domain using classical linear control design techniques (Ogata 1970). The design model included rigid-body modes, second-order actuation models, and filter dynamics. Lead-lag filters were included to improve stability margins. Attenuation at the lowest structural frequency $(42 \mathrm{~Hz})$ is greater than 40 $\mathrm{dB}$, therefore no structural filters were required. The current design envelope is from the engine test condition at Mach 7 down to Mach 0.8. Continuous domain dynamics were discretized using a Tustin transformation at $100 \mathrm{~Hz}$. The control laws were primarily designed using Matlab/ Simulink* FORTRAN Code was generated for nonlinear batch simulation. After linear analyses were completed, a full nonlinear simulation analysis of the HXRV was performed. Nonlinear simulation allowed designers to uncover any limitations inherent in the linear analysis and to study effects of variations in key parameters, such as center of gravity location and dynamic pressure. The flight control laws will be autocoded into $\mathrm{C}$ from the Simulink block diagrams for flight hardware implementation.

A brief discussion of the longitudinal and lateral-directional control law architectures follows. The control laws are discussed in more detail in Selmon et al. 1998.

\section{Longitudinal Control Law}

The longitudinal control law has a classical loop structure. This control law is designed to maintain a desired angle of attack during the engine test sequence, then switches to maintaining a desired load factor $(\mathrm{Nz})$ during the descent. This is accomplished by selective augmentation of the HXRV dynamics. The angle of attack of HXRV is commanded to the desired values by means of symmetric deflection of the all-moving wing. Estimated angle of attack and measured pitch rate feedbacks are used to provide longitudinal stability. The angle of attack is commanded to 2 degrees during the test and varied according to guidance commands (nominally 8 to 14 degrees) for controlled descent and flight termination.

\footnotetext{
${ }^{*}$ Matlab and Simulink are registered trademarks of The MathWorks, Inc.
} 
A diagram of the longitudinal control law is given in Figure 5. During the engine test, input to the longitudinal control law is commanded angle of attack. During descent, input is commanded load factor. In the $\mathrm{Nz}$ command block, the commanded load factor is converted into a commanded angle of attack. The estimated AOA is subtracted from the commanded AOA to form an AOA error. This signal is multiplied by gains, then integrated. The integrator structure is used to improve angle of attack regulation. Measured pitch rate is multiplied by feedback gains. The opening of the inlet cowl door and the powering of the engine cause pitching moments and normal force disturbances that are compensated by feedfoward commands to adjust the control surface commands. The symmetric all-moving wing command is the sum of integrated AOA error, pitch rate, and disturbance compensation signals. Gains are scheduled with angle of attack and Mach number. The surface commands are compensated for changes in dynamic pressure.

\section{Lateral-Directional Control Law}

The lateral-directional control law has a classical loop structure. The control law is designed to maintain a desired bank angle and suppress undesirable directional motions. The bank angle of the HXRV is commanded to desired values by differential deflection of the all-moving wing. The commanded bank angle is zero during the engine test phase, but may be nonzero during the descent phase. Directional motions are controlled by deflection of the rudders. In the lateral channel, measured roll rate and bank angle feedbacks are used to augment lateral dynamics. In the directional channel, gravity compensated yaw rate is fed back to augment directional stability.

A diagram of the lateral-directional control law is given in Figure 6. Input to the lateral channel is commanded bank angle. Lateral channel feedbacks are bank angle and roll rate. Commanded bank angle is differenced with measured bank angle and this error is multiplied by the bank angle gain. This gain is a function of angle of attack and Mach number. Bank angle error is passed through an integrator structure to improve bank angle regulation. Measured roll rate is passed through a lead-lag filter and multiplied by feedback gains that are a function of angle of attack and Mach number. The differential all-moving wing command is the sum of the roll rate, bank angle error, and integrated bank angle error signals. Yaw due to aileron is reduced by providing an aileron-rudder-interconnect (ARI). The ARI gain is a function of angle of attack and Mach number.

The directional channel feedback is gravity compensated yaw rate. Sideslip feedback is not required because there is sufficient aerodynamic directional stability for all flight phases. The yaw rate feedback is passed through a lead-lag filter then multiplied by gains that are scheduled with angle of attack and Mach. The rudder command is the sum of this signal and the ARI command from the lateral channel. The surface commands are compensated for changes in dynamic pressure.

\section{Angle-of-Attack Estimation/Measurement}

Control of angle of attack (AOA) requires an accurate measure of AOA. Conventional AOA measurement devices cannot be used at the flight test conditions of the HXRV due to severe aerodynamic heating. Several approaches to determining an accurate measure of AOA have been considered. Four of these approaches are discussed in the following.

Aerodynamic Model Approach.

In this approach, the angle of attack of the HXRV is estimated from available measured motion data, the physical and predicted aerodynamic characteristics (wind-tunnel data, CFD, etc.) of the HXRV and atmospheric and flight condition data. Angle of attack rate is calculated from point-mass kinematics and is primarily a function of pitch rate. This AOA estimation approach combines rapid pitching motion measurements with long-term vertical acceleration measurements to produce an estimated AOA. This estimator contains a model of the lifting characteristics of HXRV that has cowl (inlet) door and propulsion effects. This approach can be sensitive to error in the derived aerodynamic parameters used to convert the normal acceleration to angle of attack.

Flush Air Data System Approach.

The Flush Air Data System (FADS) consists of pressure ports located on the upper and lower surface of the HXRV forebody. Preliminary FADS pressure port locations are given in Figure 7. Although all nine FADS ports are shown, only ports 1 through 4 are used in the flight controls to estimate angle of attack. An estimate of angle of attack is determined as a function of the pressure differential between these pressure ports, dynamic pressure, and Mach number. In this approach, the FADS angle of attack estimate would replace the aero model-based angle of attack estimate going into the complimentary filter. The angle of attack rate estimate is the same as in the aero 
model-based approach. This approach is sensitive to errors in the functional relationship between angle of attack and differential pressure.

\section{Inertial Measurement Unit Approach.}

The Inertial Measurement Unit (IMU) provides accurate measurements of the inertial velocities and attitude of the HXRV. Angle of attack is defined as the angle between the vehicle body $x$-axis and the direction of the freestream airmass velocity upstream of the vehicle. If airmass motion relative to the earth is ignored, then angle of attack can be determined directly from inertial velocities. Angle of attack is calculated to be $\arctan (w / u)$, where $w=$ inertial plunge velocity and $u=$ inertial forward velocity. In this approach, the IMU angle of attack estimate would replace the aero model-based angle of attack estimate going into the complimentary filter. The angle of attack rate estimate is the same as in the aero model-based approach. This approach is sensitive to atmospheric winds.

\section{Complimentary Filter Approach}

In this approach (Lallman et al. 1997), a complimentary filter is designed to combine signals with different content and accuracy characteristics into a composite signal with the "best" characteristics of each input signal (See Figure 8). The filter tracks a low frequency input (angle of attack) for frequencies less than $1 / \mathrm{T}$ and integrates a high frequency input (angle of attack rate) for frequencies greater than 1/T. The complimentary filter combines the two inputs to form a composite angle of attack estimate.

The Aerodynamic Model Approach is not being used because of uncertainty in the aero model data. This uncertainty would not allow calculation of the AOA to the required accuracy. The IMU Approach has been chosen as the primary source for AOA because of its close tolerances and high bandwidth. The high bandwidth of this signal eliminates the need for a Complimentary Filter Approach. The two approaches currently being considered are the Inertial Measurement Unit Approach and a Blended Inertial Measurement Unit / FADS Approach. In the Blended approach, FADS information would be used to correct the Inertial Measurement AOA for steady-state errors.

\section{Flight Control Law Evaluation}

Simulation analysis of the separation of the Hyper-X Research Vehicle (HXRV) from the Hyper-X Launch Vehicle (HXLV) has been performed extensively in order to maximize the chances of mission success and minimize risk to the Research Vehicle. Numerous parametrics and Monte Carlo analyses have been conducted and have resulted in a separation controls/sequencing strategy that satisfies the desired objectives. So far, any required changes are limited to the separation control mode and do not require any modification to the basic free flight control laws. Much of the analysis had been focussed on selecting a preferred separation scenario. The choice was between a fixed adapter scheme and a more elaborate mechanized two-piece adapter approach. The later approach attempted to eliminate the possibility of re-contact, but was ultimately deemed to be too risky and uncertain. The fixed adapter approach (Figure 9) was adopted as the preferred scenario and the separation analysis effort focussed on defining a viable fixed adapter separation strategy with sufficient robustness to handle uncertainties. The separation control strategy consists of outer loop and inner loop closure time triggers as well as an initial open-loop elevon command schedule. There is also a requirement for the HXLV to command a maximum nose down maneuver at separation to provide additional clearance margin. Final details of the separation strategy will be determined upon completion of final Monte Carlo analysis.

Current assessments of flight trajectories and stability margins for the control laws demonstrate that the HXRV meets the flight test requirements. For example, Figure 10 presents simulated symmetric AMW position and angle of attack as a function of time, from stage separation to cowl closure. This simulation uses an example engine fuel sequence to demonstrate control law performance. Initially, the HXRV is at the design separation condition of zero AOA. The symmetric AMW is set to approximately 9 degrees trailing-edge down to balance aerodynamic pitching moments. During the first 0.5 second after separation, the HXRV is propelled forward from the booster-adapter by gas-charged pistons, the control system activates and moves the symmetric AMW to 6 degrees to re-establish pitch trim. The control system commands 2 degrees AOA from this time until the end of data shown. The cowl door opens between 2.5 and 3 seconds. The symmetric AMW trim angle decreases to balance a nose-down pitching moment produced by airflow through the engine. The HXRV is held at a steady 2 degrees AOA for 5 seconds while engine-off tare data is collected. At 7.5 seconds after separation, silane ignitor and hydrogen fuel flows are initiated. The ignitor turns off at 8 seconds, while the fuel continues to ramp up to full power at 9 seconds. The operating 
engine causes a large nose-down pitching moment that is balanced by a reduction of elevator trim position to nearly zero. The engine is maintained at full power ( design fuel flow rate ) until 15.5 seconds in this simulation.

At 15.5 seconds after separation, the fuel flow is quickly turned off. The sudden loss of nose-down pitching moment from the engine causes a nose-up motion of the HXRV (increased AOA). Rapid control motions limit the pitch excursion and return the HXRV to the commanded AOA. The HXRV holds steady for another 5 second tare period. A 15 second period of programmed control surface motions is performed to generate data for post-test parameter identification (PID). The control motions are designed to highlight short period parameters with an emphasis on variations in drag forces caused by trim changes of the symmetric AMW. This drag data is needed to accurately characterize the thrusting performance of the engine. This simulation predicts that the control system properly stabilizes the HXRV for the engine test sequence. The symmetric AMW excursions are within reasonable limits. The HXRV response to commands and disturbances is acceptable for the flight test.

Single-loop stability analysis was done at the HXRV inputs. The gain and phase margins were obtained by breaking an individual loop while leaving the remaining loops closed. The analysis was done by breaking the individual physical control input commands to the actuators (symmetric and differential all-moving wings, and rudder). Gain and phase margins at nine nominal flight conditions are given in Tables 1 and 2 . As these tables show, the gain and phase margins are much better than the design guidelines of $\pm 6 \mathrm{~dB}$ and \pm 45 degrees, respectively. These margins exclude the very low frequency range of the spiral mode. The gain and phase margins evaluated at an additional 32 off-nominal flight conditions were also within the guidelines.

\section{Concluding Remarks}

This paper has presented a description of the control law architectures with performance and robustness analyses for the Hyper-X Research Vehicle. The Hyper-X needs closed-loop flight control to enable a successful stage separation, to achieve and maintain the design condition during the engine test, and to provide a controlled descent. Before contract award, NASA developed preliminary flight control laws for the Hyper-X to evaluate the feasibility of the proposed scramjet test sequence and descent trajectory. After contract award, a Boeing/NASA partnership worked to develop the current control laws. Longitudinal and lateral-directional control laws were developed for angle of attack and bank angle control, respectively. The control laws were designed in the continuous domain using classical linear control design techniques. Assessments of flight trajectories and stability margins for these control laws demonstrate that the vehicle meets the flight test requirements. Additional analyses of performance and robustness characteristics will be performed after release of final aerodynamic and actuation model updates. The first flight test at Mach 7 is planned for early 2000.

\section{References}

Lallman, F.; Davidson, J.; and Pahle, J.: Hyper-X Government Furnished Items (NAS1-97110): Preliminary (inner loop) Control Laws for Candidate Design, Deliverable H7006-M7-01-GCT, March 24, 1997, NASA Report HXGFI-001.

McClinton, et al.: NASA's Hyper-X Program. Presented at the 1997 JANNAF Joint Meetings, West Palm Beach, Florida, October 27-31, 1997.

Morelli, E.A.: Flight Test Validation of Optimal Input Design and Comparison to Conventional Inputs. AIAA 973711, AIAA AFM Conference, August 11-13,1997. New Orleans, LA.

Ogata, K.: Modern Control Engineering. Prentice-Hall, Inc., 1970.

Selmon, J.; Bose, D.; and Miranda, L.: Hyper-X Critical design Review : Flight Controls. Presented at Hyper-X Critical Design Review, Seal Beach, CA. February 2-5, 1998.

White, J.T.: Recommended HX-FADS Configuration. NASA Report HX-387, NASA Dryden Flight Research Center, September 1997. 


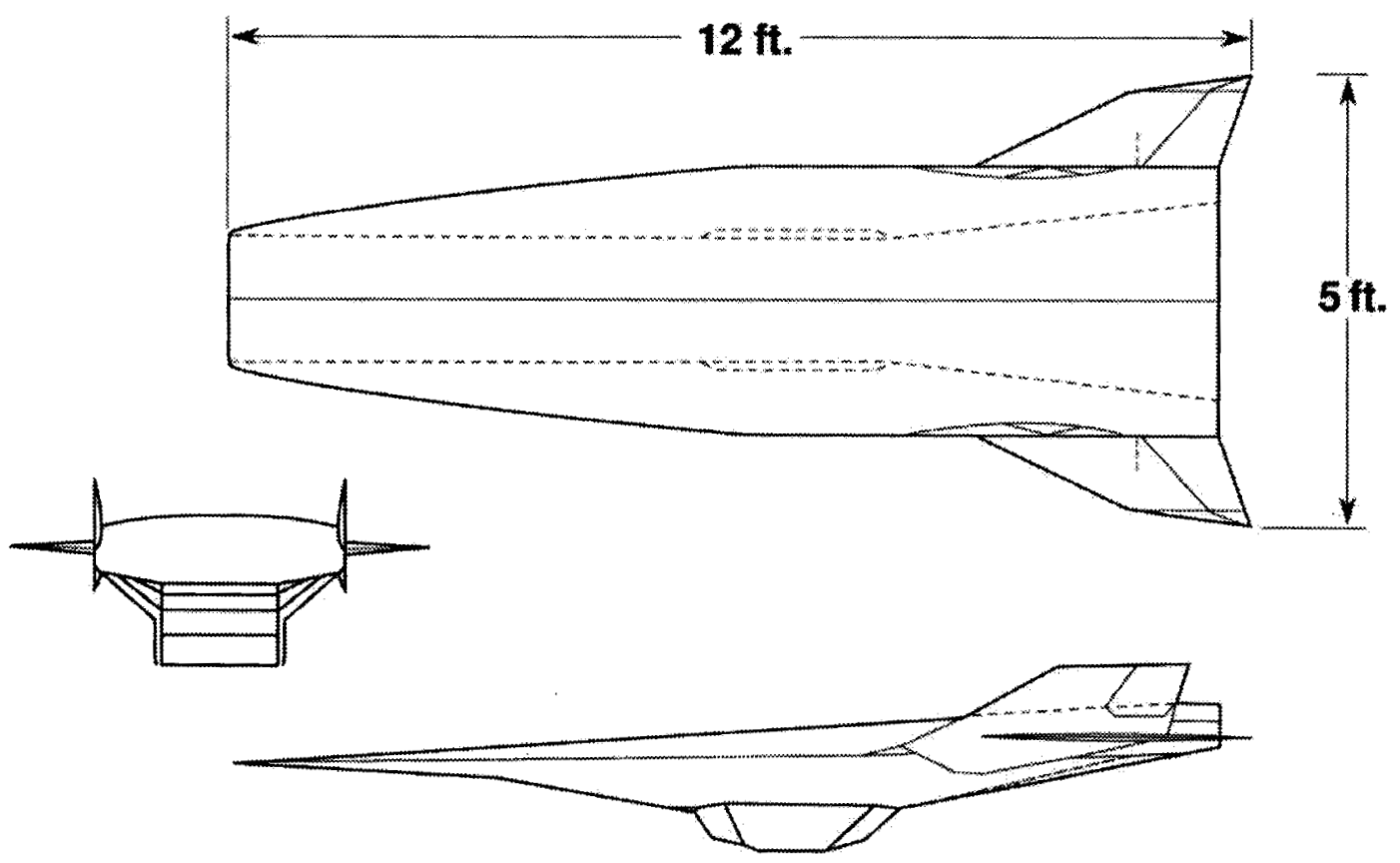

Figure 1. Hyper-X Research Vehicle (HXRV).

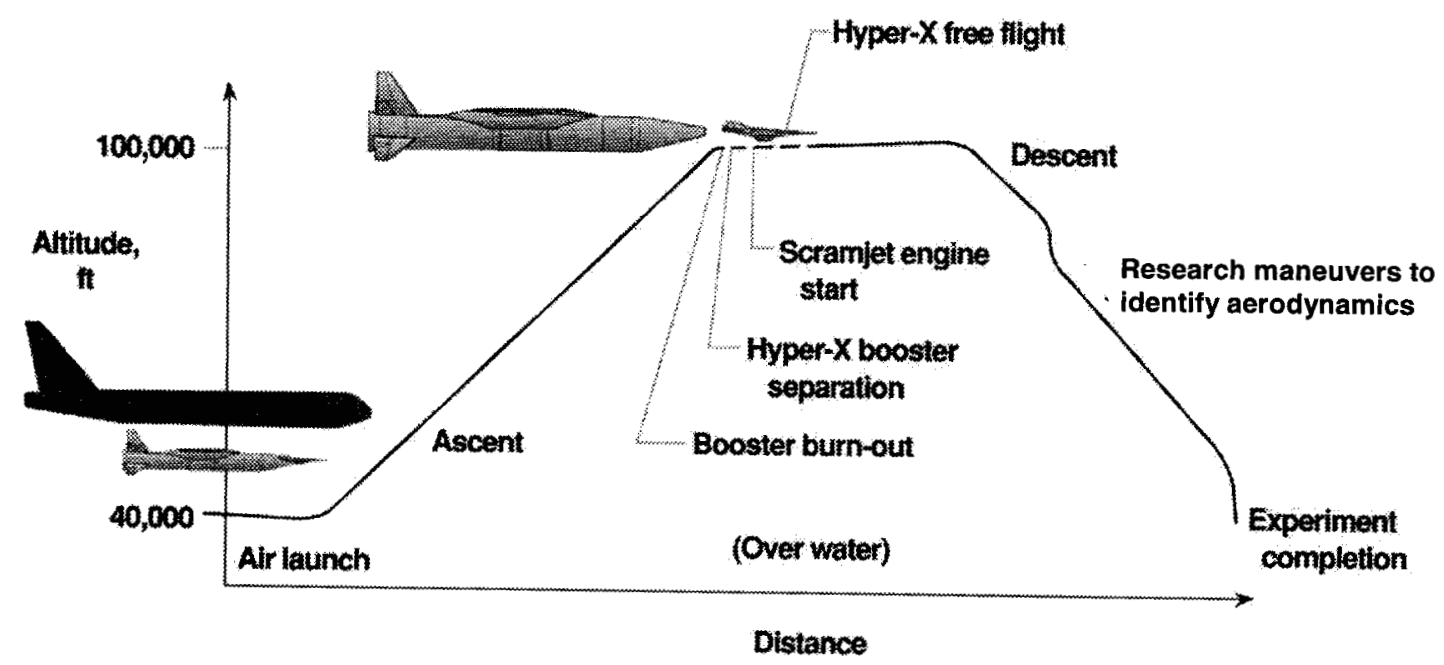

Figure 2. Hyper-X flight trajectory. 

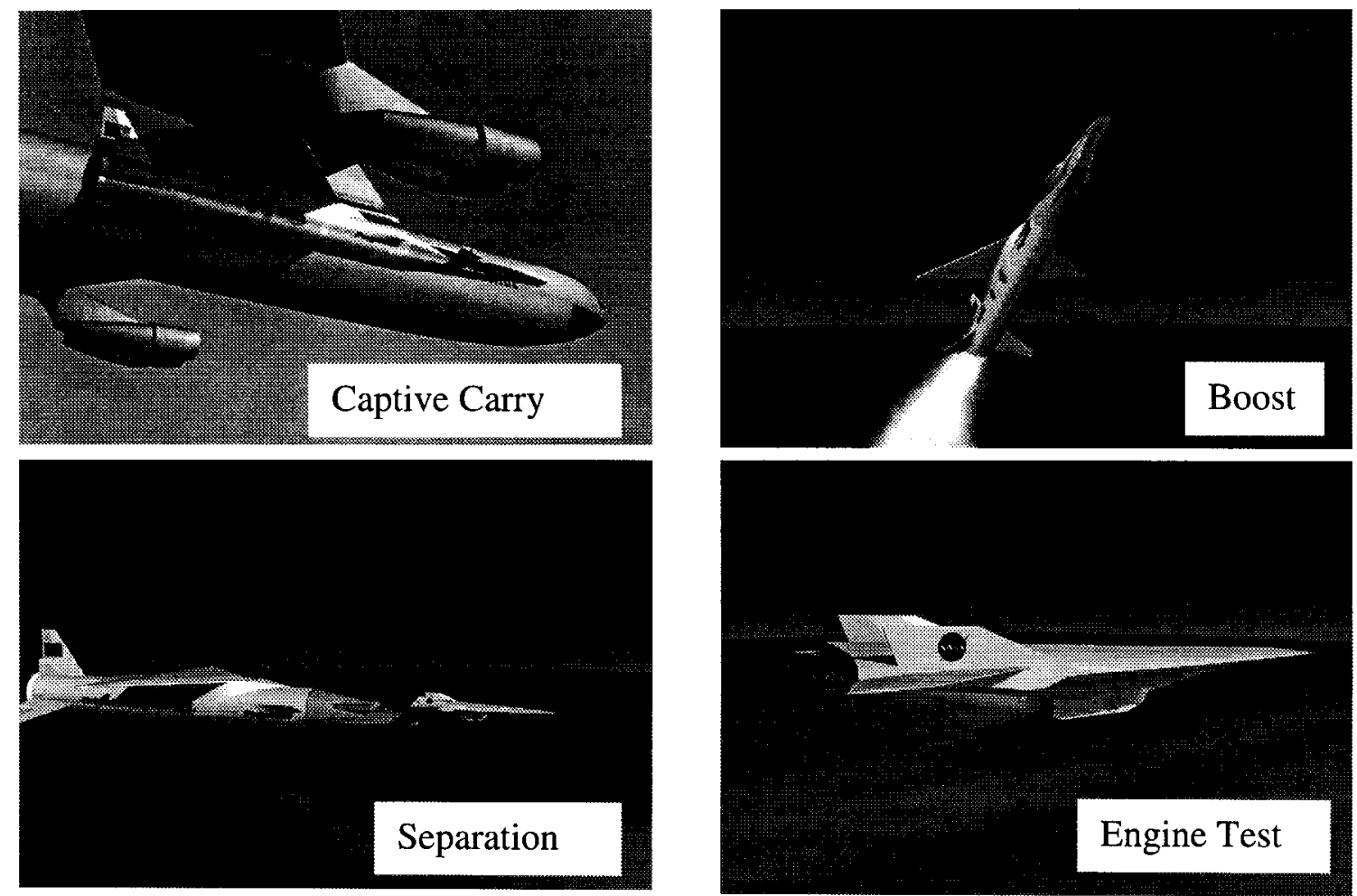

Figure 3. Hyper-X flight phases.

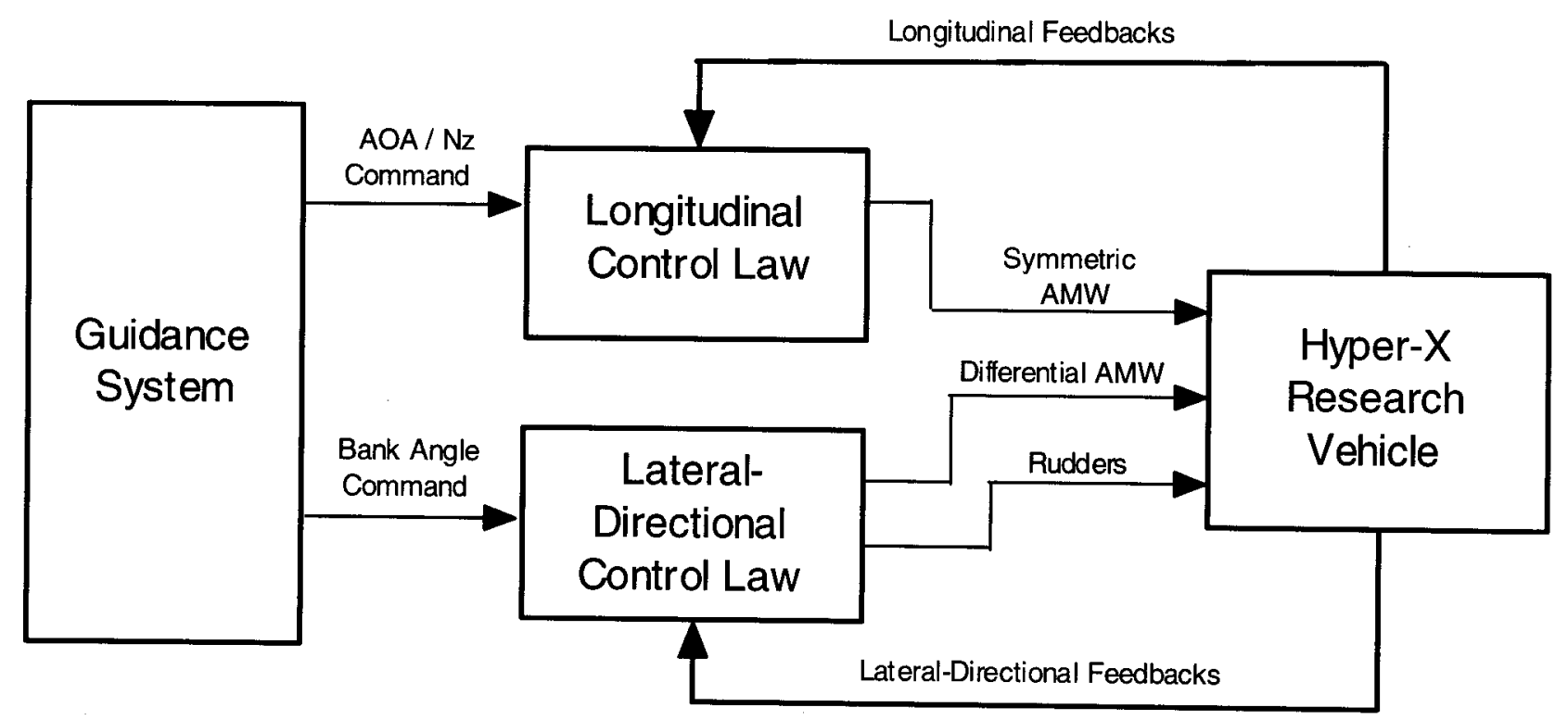

Figure 4. Flight control law overview. 


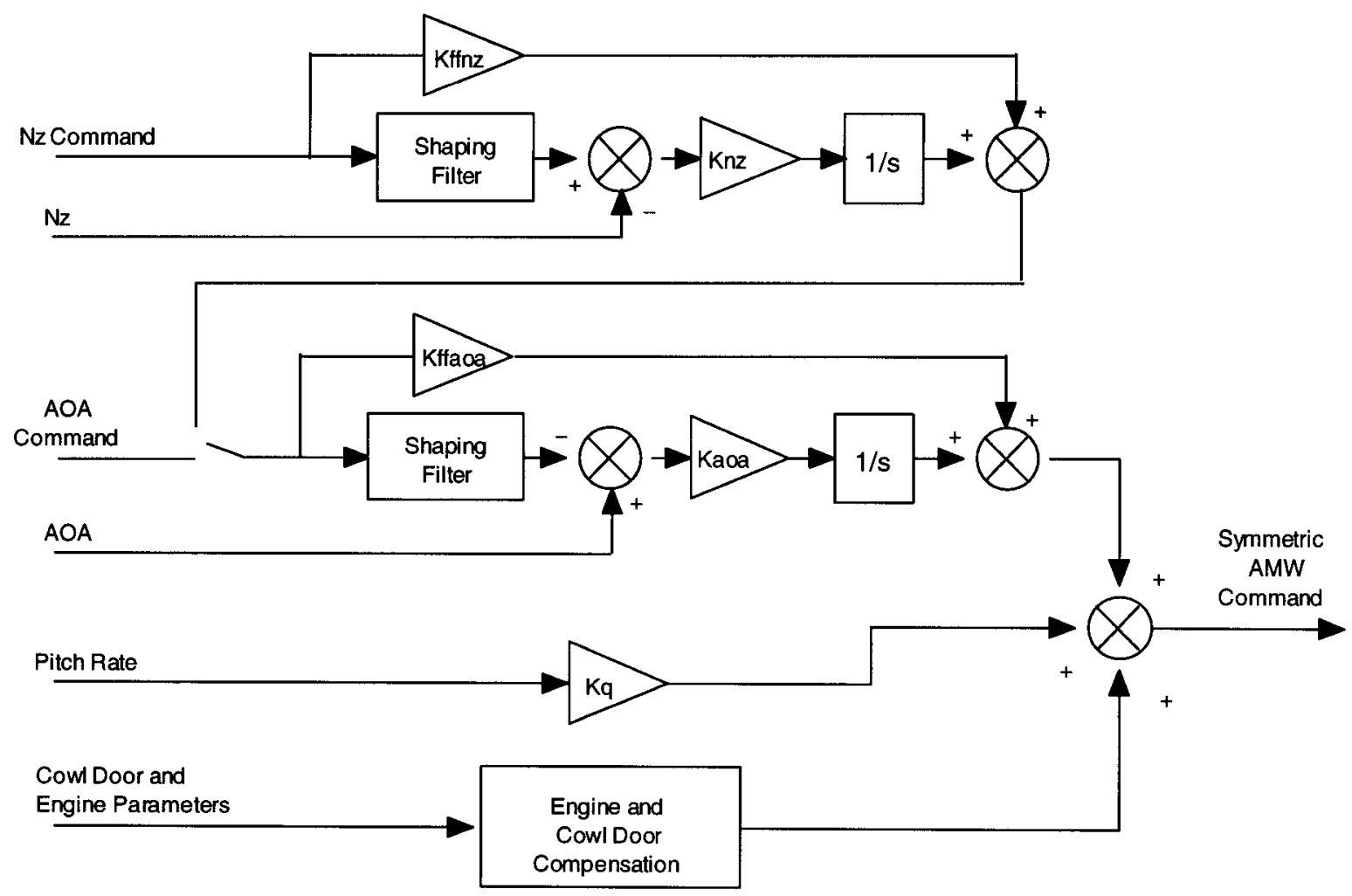

Figure 5. Longitudinal control law overview.

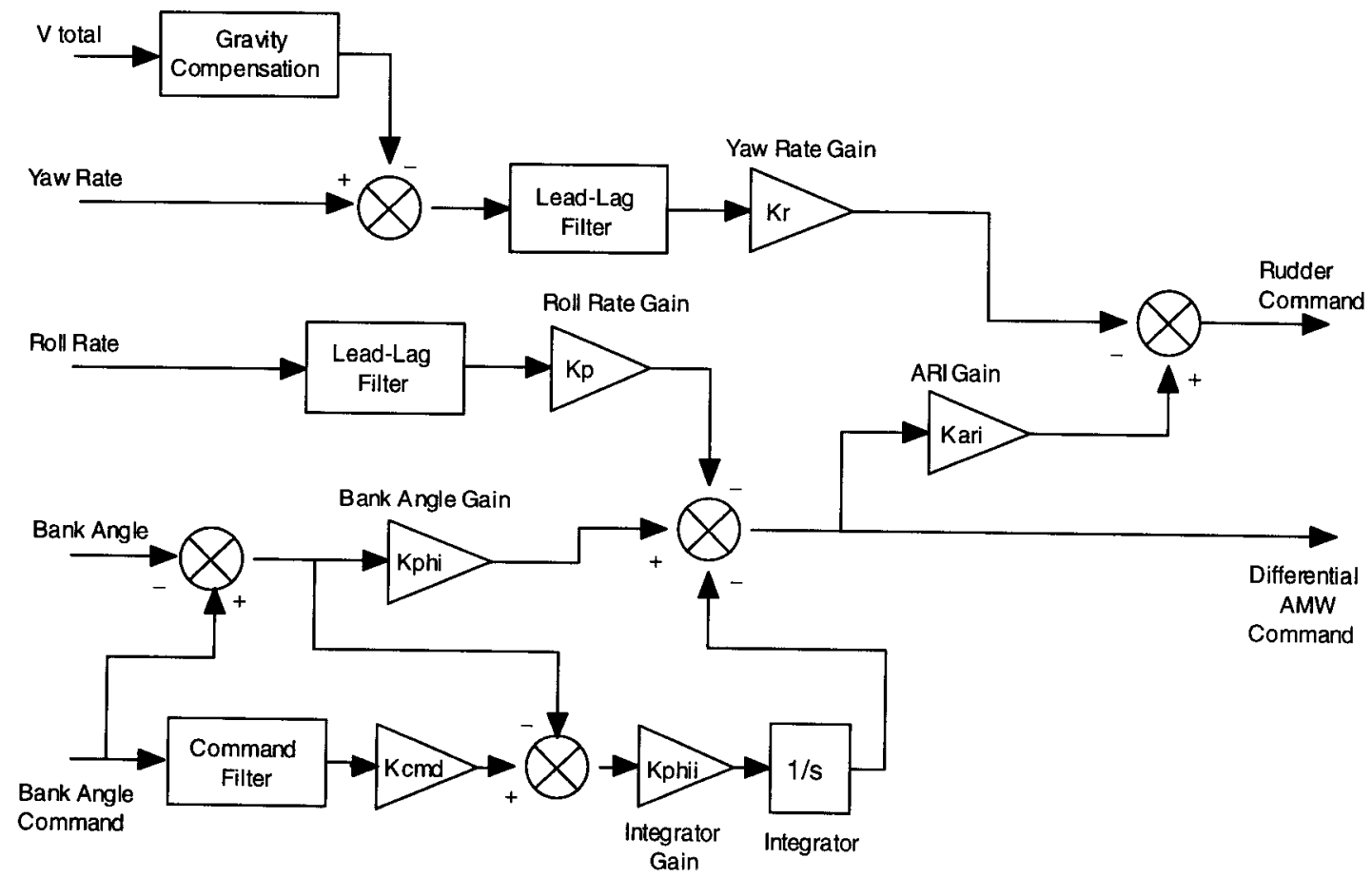

Figure 6. Lateral-directional control law overview. 


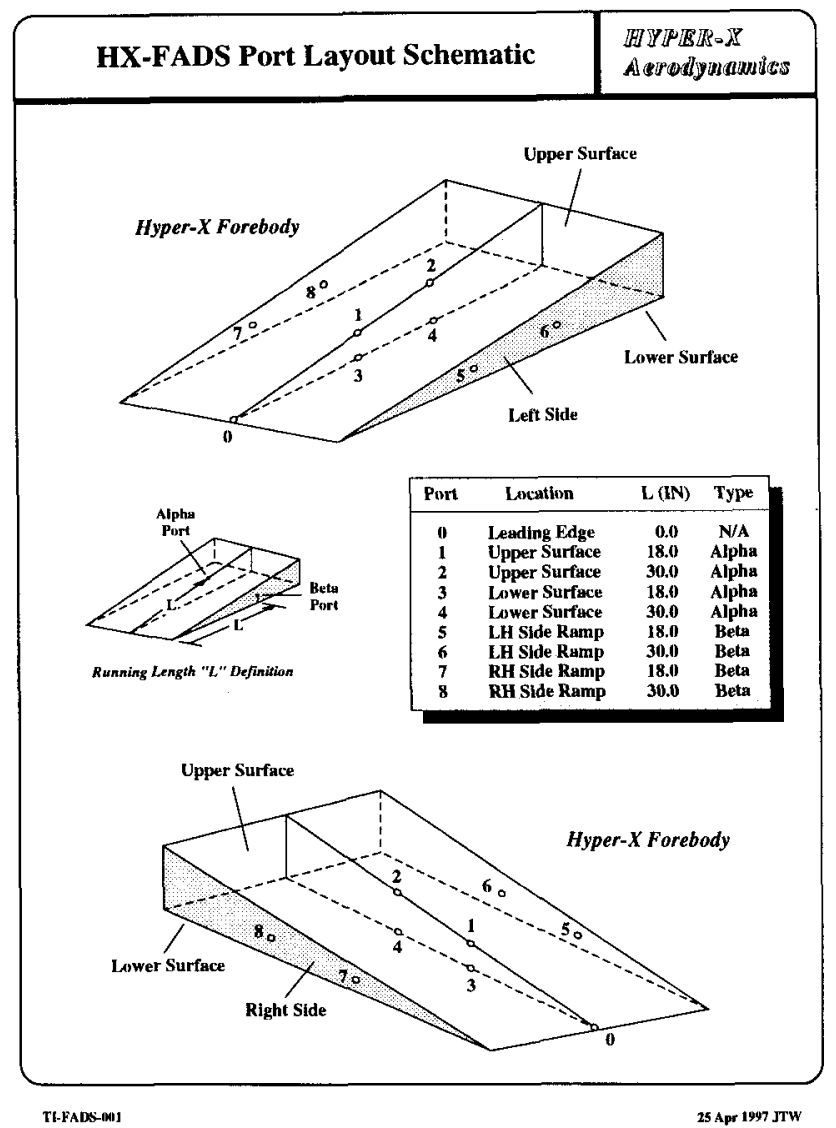

Figure 7. Preliminary Flush Air Data System (FADS) port locations.

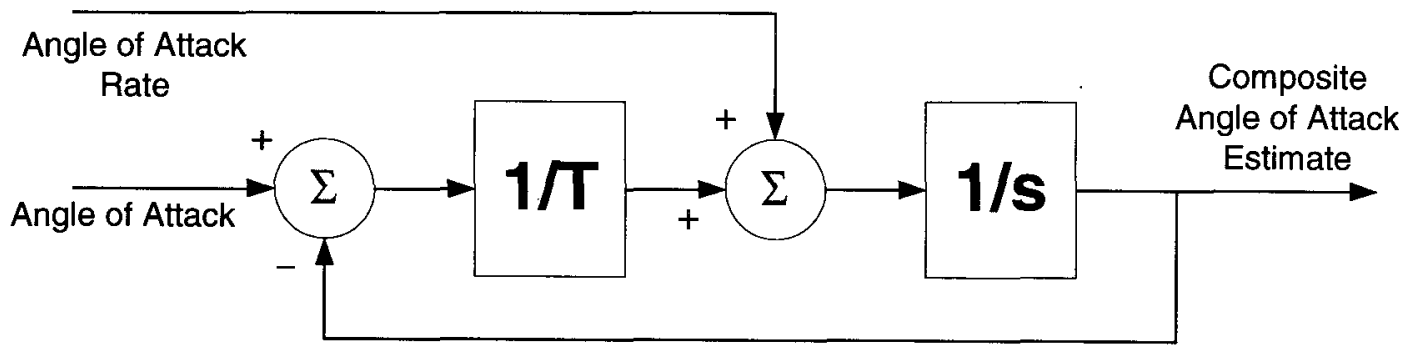

Figure 8. Angle of attack estimator using a first-order complimentary filter. 
Fixed Jaw Separation

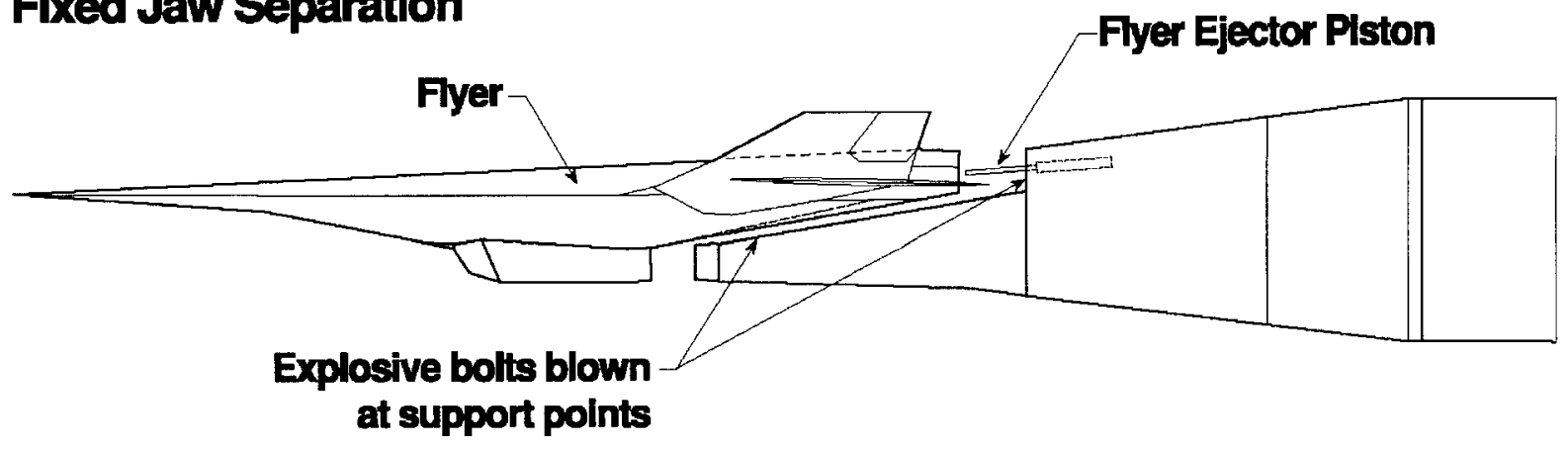

Figure 9. Current Separation Scenario.
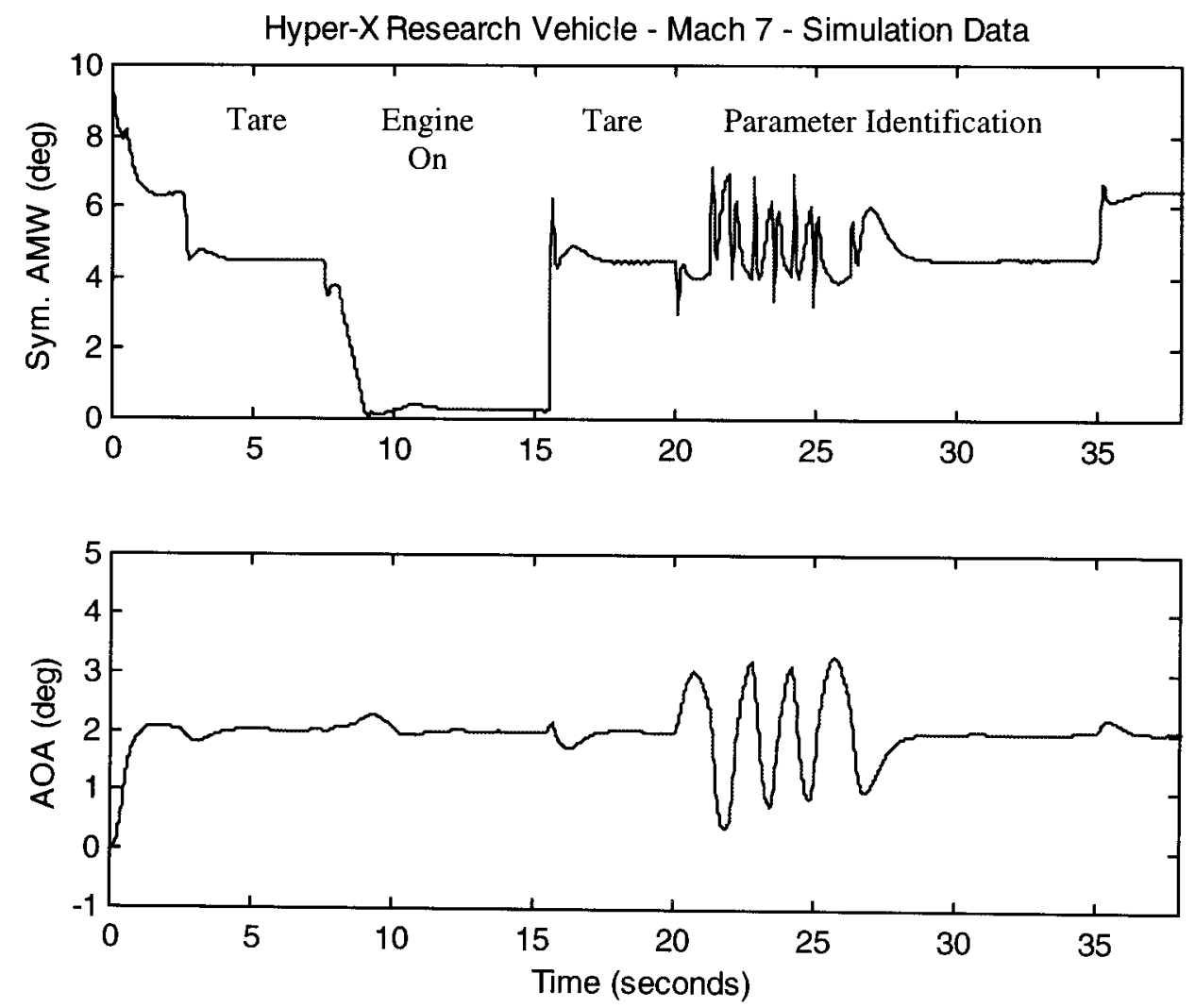

Figure 10. Symmetric all-moving wing and angle of attack time responses. 
Table 1. Longitudinal Gain and Phase Margins at Nominal Flight Conditions

\begin{tabular}{|c|c|c|c|c|c|c|}
\hline Mach & $\begin{array}{c}\text { AOA } \\
(\mathrm{deg})\end{array}$ & $\begin{array}{c}\text { Qbar } \\
(\mathrm{psf})\end{array}$ & $\begin{array}{c}\text { Altitude } \\
(\mathrm{ft})\end{array}$ & $\begin{array}{c}\text { Gain Margin } \\
(\mathrm{db})\end{array}$ & $\begin{array}{c}\text { Phase Margin } \\
(\mathrm{deg})\end{array}$ & $\begin{array}{c}\text { Phase Margin } \\
\text { Frequency }(\mathrm{r} / \mathrm{s})\end{array}$ \\
\hline \hline 7 & 2 & 1000 & 95000 & $10.9(10.8)$ & $66.2(63.5)$ & $9.8(10.7)$ \\
\hline 7 & 2 & 1400 & 87850 & $10.8(10.8)$ & $64.3(61.9)$ & $10.6(11.4)$ \\
\hline 7 & 8 & 1600 & 84850 & 9.4 & 54.1 & 7.5 \\
\hline 7 & 8 & 1800 & 82400 & 8.6 & 54.2 & 7.4 \\
\hline 6 & 8 & 1000 & 88300 & 11.2 & 54.5 & 7.3 \\
\hline 5 & 8 & 1000 & 80500 & 10.2 & 60.0 & 9.4 \\
\hline 4 & 8 & 800 & 75800 & 9.3 & 61.7 & 11.3 \\
\hline 3 & 8 & 800 & 63700 & 9.0 & 60.7 & 11.8 \\
\hline 2 & 8 & 800 & 46700 & 9.6 & 61.5 & \\
\hline
\end{tabular}

(.) Cowl Door Open/Engine On

Table 2. Lateral-Directional Gain and Phase Margins at Nominal Flight Conditions

Aileron Loop

\begin{tabular}{|c|c|c|c|c|c|c|}
\hline Mach & $\begin{array}{c}\text { AOA } \\
(\mathrm{deg})\end{array}$ & $\begin{array}{c}\text { Qbar } \\
(\mathrm{psf})\end{array}$ & $\begin{array}{c}\text { Altitude } \\
(\mathrm{ft})\end{array}$ & $\begin{array}{c}\text { Gain Margin } \\
(\mathrm{db})\end{array}$ & $\begin{array}{c}\text { Phase Margin } \\
(\mathrm{deg})\end{array}$ & $\begin{array}{c}\text { Phase Margin } \\
\text { Frequency }(\mathrm{r} / \mathrm{s})\end{array}$ \\
\hline 7 & 2 & 1000 & 95000 & 14.9 & 83.8 & 3.3 \\
\hline 7 & 2 & 1400 & 87850 & 14.7 & 78.7 & 3.2 \\
\hline 7 & 8 & 1600 & 84850 & 10.2 & 63.1 & 12.4 \\
\hline 7 & 8 & 1800 & 82400 & 10.1 & 61.9 & 12.9 \\
\hline 6 & 8 & 1000 & 88300 & 11.4 & 64.2 & 10.0 \\
\hline 5 & 8 & 1000 & 80500 & 10.7 & 73.0 & 10.9 \\
\hline 4 & 8 & 800 & 75800 & 9.9 & 83.5 & 10.9 \\
\hline 3 & 8 & 800 & 63700 & 12.3 & 115.5 & 1.1 \\
\hline 2 & 8 & 800 & 46700 & 12.6 & 115.2 & 0.7 \\
\hline
\end{tabular}

Rudder Loop

\begin{tabular}{|c|c|c|c|c|c|c|}
\hline Mach & $\begin{array}{c}\text { AOA } \\
(\mathrm{deg})\end{array}$ & $\begin{array}{c}\text { Qbar } \\
(\mathrm{psf})\end{array}$ & $\begin{array}{c}\text { Altitude } \\
(\mathrm{ft})\end{array}$ & $\begin{array}{c}\text { Gain Margin } \\
(\mathrm{db})\end{array}$ & $\begin{array}{c}\text { Phase Margin } \\
(\mathrm{deg})\end{array}$ & $\begin{array}{c}\text { Phase Margin } \\
\text { Frequency }(\mathrm{r} / \mathrm{s})\end{array}$ \\
\hline 7 & 2 & 1000 & 95000 & 10.8 & 74.0 & 9.3 \\
\hline 7 & 2 & 1400 & 87850 & 9.2 & 65.7 & 11.3 \\
\hline 7 & 8 & 1600 & 84850 & 23.4 & Inf & - \\
\hline 7 & 8 & 1800 & 82400 & 22.8 & Inf & - \\
\hline 6 & 8 & 1000 & 88300 & 31.8 & Inf & - \\
\hline 5 & 8 & 1000 & 80500 & 18.2 & Inf & - \\
\hline 4 & 8 & 800 & 75800 & 14.7 & Inf & - \\
\hline 3 & 8 & 800 & 63700 & 11.6 & 90.2 & 11.1 \\
\hline 2 & 8 & 800 & 46700 & 8.2 & 61.2 & 14.6 \\
\hline
\end{tabular}

